\title{
Gilding the Algorithm?
}

So far we have considered terms like 'Day One' and 'flywheel', we have looked at multipliers and I have suggested the term 'the algorithmic state'. Here I am suggesting that this is like the Gilded Age of the late nineteenth century in the USA but multiplied. Where in the Gilded Age there were essentially single activity entities like railroads Amazon is now operating in multiple dimensions, the algorithms working to take the entity into more and more spheres in faster and faster ways.

There are negative multipliers like Covid and positive multipliers like Alexa and we go back to the comparison made with followers of the Maori King in the nineteenth century. In the latter case there were also widespread health issues, land confiscation and war on the negative side and a discovery of shared interest on the positive side to act as multipliers.

Positive or negative though, by good luck or bad management a multiplier is a multiplier and the stars have aligned for Amazon in many ways. Some ways may be simply put as in good data and good systems.

We might though, as an exercise, think about where multipliers are NOT working for Amazon to start with or

Professor Peter Cleave is a Research Associate in the Faculty of Health and Environmental Sciences (AUT University), a Visiting Fellow in Te Ara

Poutama (AUT University), a Member of Common Room, Wolfson College (Oxford University), and a Broadcaster in Te Reo Maori at Kia Ora FM. 
at least where the goal seems always out of reach. Right now that is in such areas as 'deep bin picking' discussed below or in what is known as 'the last mile'. The idea of 'the last mile' is important and keeps coming up. We are talking about delivery direct to refrigerator, ePalette self driving vehicles and scouts, the little autonomous delivery vehicles and personal lock boxes all reducing 'the last mile'. This is just a matter of getting the product to the client in a satisfactory way but the business of actually getting the product into the hand of the client seems elusive. Robot to robot interaction might be considered where the in house robot accepts delivery from the robot without.

'Deep bin picking; or' the last mile' are like voice recognition- nearly there but not quite yet. When they do get 'there', to a place where they work seamlessly and in real time then the algorithmic state will have greater dimension as things work without glitches. Then it will be on to enhance customer satisfaction, to improve the customer experience once the nets and bolts of the operation are actually in place and functioning.

Another multiplier, so far not maximised is facial recognition. An example is Color IQ which uses facial scans and then suggests how to improve things. Facial recognition is becoming important especially in China with Alibaba and its Smile to Pay for KFC in China. This makes shopping easier in store but could also be used on line. The slow take up of facial recognition in the USA by contrast with China illustrates a significant difference; the ideology of freedom in the USA is an obstacle to the algorithm involved in facial recognition, there is a political cap on this data. Again, it is a state impediment for the algorithms to get around...

While Amazon may not be into facial recognition at least not in the USA, it seems, potentially, to be a useful add on to Alexa. And/or a potential add on at the Amazon Go 
Cafes. It's more of a question of what to add to what. Amazon now offers a multiplicity of developmental points and that in itself is a kind of multiplier. Here we have a scale of diverse activities as well a sheer scale of volume.

Sometimes a convenience turns into a multiplier. For example there is no Check out in Amazon Go cafes. So the client walks in takes what is required from the shelf and walks out. No queue. All by phone. While this has not so far reached the supermarket it seems so convenient as to be just a matter of time.

And robots increasingly recognise things. Dumaine gives (2020:172) the example of recognising redness and hence ripeness in strawberries. Again, the human factor is knocked out of the equation.

Then there is the question; what is Amazon listening for? Alexa has filed a patent to pick up a sniffle or a cough and we could talk about this later in the discussion of Amazon and health. The entry into the intimacy, the viscera of the person is illustrated by this example.

Amongst this set of 'nearly-but-not-quite-theres' drones are still not maximised. This is curious and looking at the key texts discussed here comparisons might be drawn. Hart in his book The Warehouse (2019) has drones in high profile. They connect the hubs and are vital parts of the transport infrastructure. There is not such an emphasis on drones although they do feature in Dumaine's work (Dumaine 2020). The argument here is that they are or at least they might be critical change agents. They obviate road transport as well as sea transport. Drones accordingly reduce the significance of the city as a transport nexus. They cut out the human factor, at least in the air if not in a control screen of some kind. But as discussed elsewhere in this series as an important example, drones, at least as far as open sky work in the USA if not in other countries like England where there 
seem few obstacles and indoors in the Fulfilment Centres all around the world are still not quite here yet.

These loose ends, these ventures that have not quite arrived belie a sense of system about Amazon. We may not understand it fully but Amazon seems to leap and surge in ways that satisfy us. Let's think about Amazon as offering something like 'the great grid'. Just as the railroad cartels in the Gilded Age offered a great grid of efficiency across America where before there had been a mishmash of companies and players Amazon offers a data zone which is sufficiently organised to satisfy us better than anything else just as it tantalises us with things it is reaching for but not quite grasping.

We might go back to Edmond Morris and his book Theodore Rex (2002) for more on the grid, we could go back to Lina Khan (2017) and the idea that the world is running on Amazon's rails and note that things are more international now. There is an internet that surpasses the nation state so that the boundaries of the railroads contained within nation states may not apply. As we read further we might turn to Becks's work on cosmopolitanism (Beck 2000) and ask whether the algorithms work to effect cosmopolitanism and reduce nationalism or at least to reduce the bounds of the nation-state.

There is a general question as to what controls do apply? Other algorithms? Regulation of tech by governments seems difficult generally speaking but in the case of Amazon there are a number of additional factors to do with the sheer scale of the company and its spread to cloud and other activities. Amazon and its algorithms seem to be in a space without borders. In the course of this series several controls are suggested in the Indian Example, the German Example, the Political Cap with sensitivity over facial recognition and voice and body noise such as coughing and the state law as with the Stop 
Bezos Act. There is also the European Union Example which echoes Khan's argument about dominance in the US market in Europe discussed below and in the next section.

The grids of the great companies and those of the nation states do not, these days, always map neatly onto one another. We might come back again to the question as to whether Amazon needs the USA and to questions of dependence. Does Amazon depend on labour in the USA? Does it depend on sales in the USA? Does Amazon depend on politics in the USA? There is a suspicion at least in the Trump-Bezos stand off and elsewhere that something does not add up, does not map, does not square with the interests of the nation state, the USA.

Basic questions of society and politics come to mind. As citizens people are members of a nation state. As customers they might be members of a club, a rewards system. What is the difference between the two, or the similarities for that matter, between what Amazon offers and what a state offers? Here the answer offered is that they both offer satisfaction for the human condition. We need to have clarification for both parts of this, what do we mean by 'satisfaction' and what do we mean by 'the human condition'?

Coming at the question in terms of the algorithm and the human with another question, is the latter cobot or consumer? Or both? Might we speak of a cobotic condition in which humans depend on algorithms through the likes of Amazon and make decisions, political and otherwise informed by AI and algorithms? Can algorithms learn progressively about the human condition and increasingly satisfy human needs? Might we be talking about consumer farms with people on Universal Basic Income supplied by algorithmic and Artificial Intelligence operations that extend to food production as well as other human needs as time goes by, 
consumer farms that function, primarily to consume with the occasional tilt at being cobotic?

This is all in a context of pro and con, of biffo across the usual geo-political suspects as we know them now. Just as it looks as if globalisation will surge ahead nationalism rears its head as in the USA with Trump and Make America Great Again. In this day of 'slowbalisation' Amazon offers order across national borders. Amazon offers membership. What is this? Membership systems now become more than pleasant fripperies. Walmart's Jetblack sits beside Amazon's Prime is a particular space, each with their own territorial influence, coast or hinterland in the USA, as discussed immediately below. How will we know geo-politics? Through nation-state or borders or tech-state areas of influence?

Talking of Walmart and Amazon, there is a division, a partition of America and the world somewhat like the partition of Africa in the 1880 s. Sometimes this is to do with having warehouses near cities. In the USA Amazon takes the coast and Walmart takes the area between. Across the globe Amazon shares space with, say, Alibaba in parts of Asia. Is this like tribalisation or retribalisation where new configurations of power in specific and not so specific places happens with new combinations of interest and locale? To carry on with physical space being divided on a global basis, Alibaba and JD take China, Amazon has Europe and shares Britain with Tesco. India is shared between Amazon, Walmart and Alibaba.

And there is the non-specific space of the internet, of cyberspace, of the cloud. How might that be divided or made into sectors? Then it is on to outer space, to what state will the trillion people imagined by Bezos to live in his version of space exploration belong?

But even with physical, geographical space there is no Berlin Conference, no grouping of great companies to sort 
out who goes where apart from isolated cases like the German Example, The EU Example or the IndiaSingapore Examples mentioned above and discussed throughout this presentation. The algorithms employed will find their own niches, work their own spaces, eat their own data.

We might talk about time as well as physical space. Is Amazon offering service forever? Service over space and time? One thinks of Bezos' 10,000 year clock. Also of what I have called the Amazon paradox or apparent contradiction of staying in Day One for the long term.

And as well as physical space on this planet there is the mission of Bezos in space which is to save humanity from itself on earth. Here you can see an ideology in Bezos which goes beyond making the next dollar in a faster, more efficient way. How do algorithms fit into such a vision? We could go back to questions of anchors and orbits. What are the anchors based upon? Where are they set? What are the orbits going around? Where is the best developmental space for Amazon? The algorithms are learning the answers.

Regarding algorithms we could ask again whether they are authorities. This goes with a sense of trust and a ready acceptance of their findings, suggestions and analyses. When we come to the Amazon saying or mantra, 'In Data we trust', we might also say we trust in algorithms to crunch the data. The best developmental space for Amazon might be where data and algorithm are optimised. That could be in a physical location as with the Head-Office-in-New-York or-where (?) idea or it could be in cyberspace as in the cloud or it could be in outer space as in the establishment of communications satellites around the globe to serve as platforms for ventures further into outer space. 
Again it might pay to look at the odd man out, the case that does not work for instruction. Health, for example. Health is problematic but Bezos is in there. It may be that Amazon would be advised to attempt an entry into health in a country other than the USA although Dumaine and others do not seem to consider this preferring, to look at the considerable difficulties there. The USA might simply be too complex and resistant.

So what might be done with algorithms in the field of health? Is there a need for a great grid that everyone understands and runs along rather than a plethora of complications in US Health and could Amazon through Haven or whatever cut through that? 228 Or is it simply a matter of gaining a presence in a context that might have potential in the health area, Alexa in the home for example and waiting for the moment say, when Alexa is given permission to report sniffles and then proceeds to provide remedies.

This, in a roundabout way, gets us to Huxley. In Brave New World (1998) there is the use of soma. If the algorithms work to keep people happy and if Amazon does move into health then the prospect of medicating, possibly through Alexa raises its head...

Is Haven a toy for a couple of rich guys or are the toys running the boys? Speaking of which or whom, over there in the corner or up there in the material world are these guys, these, mainly, boys with their toys, these technauts, real estate developers and grifters of scaleBezos, Musk, Gates, Ma, Jobs and those of their financial dimension like Trump or Epstein, are these the key agents, people of genius, masters of authority or are they themselves working to the beat and tune of the algorithm?

Coming back to the idea of entering the health field, one door seems to imply the opening of another. The Amazon 
health Savings Card takes Amazon further into banking with 1-Click. Savings and banking offer another doorway. Amazon is already lending to merchants in American markets. Amazon owns a Visa card with Chase and people could ask 'Hello Alexa what's my bank balance?' A step into convenience here, a step there into happiness there, the algorithms figure out the satisfaction equations and become, as they do so, the authorities, the go to agents. The owners of the algorithms, 'these guys' themselves, become cobots in the process.

At this stage of its development Amazon can take a step by step approach across fairly wide domains, domains that evoke the idea of a state wide economy;

Bezos is using what Bain \& Co.'s Orit Gadiesh called "profit pools" - a tool that shows profit margins at each stage of the value chain, and asks senior managers to ask, 'where is the money [today]?' and 'where will the money be in 5 years?'? This is precisely what Bezos asked. His answer: creating download content. And he is able to move Amazon, with alacrity and skill, to where the money will be.

Maital, Shlomo

https://timnovate.com/tag/bain/

How extensive will the profit pool be? How far is it from one step to another? With the digital showroom on its Amazon site, not far. Sometimes the step is a rephrasing. The idea that Amazon could be a rival to Fedex in shipping just seems a recasting of existing freight operations...

To sum up the argument so far in this section, Amazon satisfies demand to a considerable if not astonishing level. In its shortcomings Amazon shows how close it is to a multifaceted satisfaction blanket looking after matters from food to entertainment and offering a market 
of a scale not hitherto seen. These are all powered by algorithms that feed on data that Amazon collects more extensively than anyone else. Amazon stores data in ways that states do not and in a scale hitherto not seen. We might ask again- what is Amazon?

To continue the discussion of algorithms and AI, AI algorithms optimise movement in the warehouse. There is a reach to employees as with radio vest frequency. As noted above robots will eventually get into 'deep bin picking'. In fact, JD Com in Shanghai China has 200000 packages per day using only standard sized packages with only 4 employees, four cobots. This, the Shanghai Example, is perhaps one of the most telling 'optimisations'.

Many things about Amazon can be copied including the management tools such as the 6 pager. But data is capital and Amazon has data of scale which may not easily be copied. Can you copy trust? We could ask where is the loyalty of Amazon, what is its loyalty programme, what does Prime have in its obligations for operators, for customers? A state gives people a sense of belonging. So does Prime. Which is most trusted?

In 1989 I wrote a book called The Sovereignty Game (Cleave 1989). To what extent is sovereignty, the sovereignty of states, a matter for Bezonomics as described by Dumaine. If the sovereignty of states gets in the way of the flywheel what does Amazon become? Is Amazon inherently stateless by virtue of its algorithms which only recognise a nation state in terms of market access, development and dominance. Or is this another animal?

Actually the debate now shifts to Universal Basic Income. We might turn to Chris Hughes' book Fair Short as recommended by Dumaine. Or we might go back to Hart's The Warehouse (2019)where people are fortunate to find 
a job in a warehouse as there are no jobs elsewhere. Going forwared from the description in Hart's book and going back to the discussion of the Stop Bezos Act the state we may be talking about may be one of dependence and satisfaction, a long way away from the means of production. The latter seem, in some respects at least, to be historical.

Where to put Amazon? New York? There are two, at least, Points Of View. The first is that if Michael Giancarnis'when they come in and take over a community like this...' The second is that of Carney for Amazon who says 'we pulled out because it wasn't worth the grief'. Dumaine notes that spending months and even years trying to appease the politicians only takes time and resources away from Amazon's focus on its customers. We might add this as the New York Example, the case of the city as distinct from the nation or nations, from the Indian Example or the German Example of wins and losses internationally for Bezos and Amazon. Across these examples the algorithms sort out, indicate and prioritize ways forward

What is the scale here? Dumaine goes back to the Dutch East United East India Company from 1602 until 1799. This is important as we see a small country and a big company and we could refer back to the points made about Nauru and the Cook Islands in Part One of this series, These mighty corporations lasted for centuries bases in small countries and there was not, then at least, the need to be in a big country like the USA.

Dumaine (ibid 217) notes that Amazon is the first company where computers have the potential to make more business decisions than humans. At a Senate Hearing in late 2020 Sen. Amy Globuchar spoke of 'algorithm review' in questioning Mark Zuckerberg of Facebook asking him how many humans were involved in review processes. He said he would get back to her. At 
this point the word 'cobotic' starts to have a torque. To go back to the novelists again this is like Wells with machines and men locked, with machines possibly in the ascendant. Also, with a dash of the dystopian it is like Huxley with Alexa dealing the soma, the happiness pills perhaps if Amazon enters health in such a way to take the edge of 'the review processes'.

All of this pertains to notions of the self as well as the state and I refer to earlier work on the remote self (Cleave, Books and Books No 31). Alexa has potential in the self image area and we go back to Black Mirror Season Two Number One and also work by Tirole (2020). What are the personal identity needs serviced by Amazon? It is argued that the situation of the individual and the group is critical and that Alexa may be the most potent and original as well as life-changing portal that Amazon has offered to the client to step through. Again we come back to the state and the machine in terms of the self. The machine in this case is the algorithm...

So many philosophies are at stake. The idea of externality, for example, with the person relating and in some respects now deferring to the algorithm. This might put us into a consideration of self, the volitional self or the passive or dependent self or even the received self. The self as a (Western?) conceit. There is a sense of realisation before conceptualisation- people depend on Alexa before thinking about what Alexa is and what she might bring beside the happiness of the moment.

Are the needs serviced by Amazon something of a data trap? We might turn to some recent analysis by Rhian Hunt discussing the market expert Levine;

'Citing the fact that sponsored listings make up between $85 \%$ and $90 \%$ of Amazon's modern business model and noting it's Amazon's ad business that's driving profits, Levine said, "an advertiser pays for higher placement 
within the sort order, the user stays on AMZN, and AMZN keeps the transaction and transaction data." He believes this calculus makes the retailer the current "best megacap on a multi-year basis."

This research led Levine to his $\$ 4,500$ price target, though he also asserts Amazon's shares won't climb to this level until approximately 2024.

Amazon's growth certainly seems to be making great strides this year, in part thanks to COVID-19's powerful acceleration of the switch from in-store shopping to ecommerce. Amazon's upcoming Prime Day could reap record-breaking profits for the company as COVID-19, growing Prime memberships, and other factors come together for a major retail boost. '

Hunt, Rhian TMR 30.10.2020

Having nodded in the direction of happiness with Huxley, Hsieh, Postman and others in mind we might look back on Wells and others in the science fiction universe and see that that they got the machine thing right, the machine in service and the service to the machine, in certain respects. Algorithms are showing us who we are. The algorithm is learning from the client organising the shape of self as indices of happiness, personality and satisfaction are formed. There is a shaping of consciousness, of the awareness of the self in groups following Tirole (ibid) and thinking about bundling.

There is a creation of the consciousness to be served and here customer service takes a turn. There is also the forming of self and group, self and community going on. Is all this Orwellian or Wellsian? In many respects the idea of the algorithmic state seems to go to Wells (1923, 2001) rather than Orwell (1949). Rather than or at least as much as sinister political forces we have the intelligent but mindless machine in the algorithmic state. It is a mix of the brave new world that Huxley suggested and the power of the machine in Wells...not that they might have 
agreed with such a presumption. To turn to commentary on Huxley and a quote from him;

'...Dr Wells, British writer and utopian scientist, whose book Men Like Gods was an incentive for Brave New World, 'All's well that ends Wells', wrote Huxley in his letters criticising Wells for anthropological assumptions that Huxley found unrealistic'. https://nanopdf.com/download/brave-new-world$\underline{\text { 5aed } 15 \text { e520f3c_pdf }}$

We could come at this from a knowledge perspective. As Foucault (1994) saw in the nineteenth century the emergence of man so we might see here the emergence of man and machine, of the cobotic situation, of the extension or incorporation of machine into mind. Foucault's idea of a break in the table where man became the centre of reflection and the divine plane did not reflect truth upon the populace as an external reference for the good now changes as man reflects on the feedback from the algorithm, the algorithm extends and the knowledge universe comes to have scope and dimension not hitherto imagined.

Does this play so that the church was the point of authority outside the man and all that has happened is that it has been replaced by the machine outside the man? Who or what is the deus and what is the machina? Or do we have a new field of knowledge?

We could go back to things that Foucault may have missed, to the comment, inadvertent as it might have been by Voltaire on Vaucansun's duck mentioned in Living Dolls (Wood 2002) and see that as a break in the table, the march of the machine having continued unabated since that time which corresponds roughly with Foucault's emergence of man but in a different reading. Is this progress or a reversion? Is our conventional historiography with God or Man in prime place challenged? If so how did this happen? 
And theorists of knowledge like Foucault or, for that matter Mannheim ( $c f$. Loader 1985) were not thinking about space, about society in outer space. Earlier the low orbiting satellites that might provide internet services were described. Are they the harbingers of new forms of society and knowledge?

All of this pertains to mind. We might think of the role of algorithms in social memory and memorialisation. Taking the last first we could say that Alexa reminds or could be asked to remind us about other peoples' birthdays as a starter. Beyond that there are the references to memorial days as well as the jogging of the memory about, say, Prime Day. Here we see a potential conflict between reminding people about Prime Day, an Amazon feature, or Singles Day, an Alibaba feature. Whatever, there is the construction of a significant past using an algorithmic process.

We could turn to several theorists here. To Kenneth Foote's excellent work on memorialisation (Foote 2018) or to Li Min's work on social memory and state formation in early China for example (Min 2018). The latter might be important for the argument in this miniseries concerning the algorithmic state. How are our beginnings and ends, our key concerns and beliefs, our main events conveyed and reinforced through Alexa and other features of Amazon that run on algorithms?

We might argue that the AI and the algorithms involved have learnt to select key dates and starting points as well as end points and that they work to form historiography. Or to tell certain stories. Or just to move from zero to one in a thousand different digital sequences. Or to tell certain myths and here we might go back to a structuralism of binaries and to Levi Strauss (1966). 
Regarding the best developmental space for Amazon we could talk perhaps about the hoops of state that Amazon has encountered. One of these is stated by Khan (2017) who is looking at how Amazon jumped through the law of the state in the USA and another has been referred to as the German Example where the German government required Amazon to wait before taking action. Another has been referred to as the Indian-Singaporean example. We might talk about jumping through the hoops of the nation-state.

To our list of telling cases we might add the Irish Example, the case where a state makes things easy for Amazon on a tax basis. The algorithms following base line capitalism are going to maximise this. And then there is the multilateral context. Amazon will have several deals with several governments all informed by algorithms. It could be argued that algorithms define locale. Just as drones will go where the algorithms tell them to go, algorithms work to direct an entirety of operations to the best market conditions which may include the least regulated, best tax situations.

It has been argued above that Amazon through Alexa mainly has entered the personal space of the client in a way that states have not entered the space of the citizen. It has been suggested that the boundaries of client and citizen are overlapping in certain respects especially when it comes to the servicing of satisfaction, of happiness. This is visceral and has the immediacy of dance (Cleave 2015). There is also a religiosity here; it is always Day One and the pact with the customer is holy.

Coming back to the comparison and contrast with the gilded age', is the above gilding the algorithm as in the expression, 'gilding the lily'? Or does the algorithm need no gilding and it is at least as powerful as described above? 


\section{Bibliography}

Beck, Ulrich British Journal of Sociology No 51 Issue No 3 January/March 2000 pp 79-105Cleave, Peter Books and Books 31 21.5.20 Campus Press Youtube

https://www.facebook.com/1487263281501261/videos $\not 266721651148057$

Cleave, Peter Memory, body and dance, a review of literature www.tekaharoa.com Jan 192015

Cleave P The Sovereignty Game, Power, Knowledge and Reading the Treaty, Victoria University Press 1989

Collins, J Good to Great Random House Business 2001

Dumaine, Brian Bezonomics How Amazon is changing our lives and what the world is learning from it, Simon and Schuster 2020

Kenneth E. Foote, Kenneth E., Shadowed Ground: America's Landscapes of Violence and Tragedy Routledge 2003

Foucault, Michel The Order of Things: An Archaeology of the Human Sciences Random House 1994

Gadiesh, Oeit and GilbertMay, James L 1998 Profit pools: A fresh look at strategy Harvard Business Review May 1998

Hart, Rob The Warehouse Bantam Press 2019

Hughes, Chris Fair Shot:Rethinking Inequality and How We Earn St Martin's Press 2018

Huxley, Aldous 1998 Brave New World, Harper

Khan, Lina M. Amazon's Antitrust Paradox The Yale Law Journal 2017: 710-805

Lévi-Strauss, Claude (1966). The Savage Mind. Chicago, Illinois: University of Chicago Press

Loader, Colin The Intellectual Development of Katl Mannheim, Cambridge University Press 1985

Maital, Shlomo Jeff Bezos Follows the Money https://timnovate.com/tag/bain/

Min, Li Social Memory and State Formation in Early China, Cambridge University Press 2018

Morris, Edmond Theodore Rex Random House 2002 
Orwell, George Nineteen Eighty Four Secker and Warburg 1949

Posner Richard Antitrust Law Second Edition University of Chicago Press 2001

Tirole

Jean

https://www.tse-

fr.eu/sites/default/files/TSE/images/conference/Digi tal_conf_2020/tirole_digital_dystopia_080120.pdf

Wells HG Men Like Gods Cassell 1923

Wells, H.G. A Modern Utopia. New York, New York: Penguin Group, 2005Wood, Gaby Living Dolls, A Magical History of the Quest for Mechanical Life Faber and Faber 2002

\section{Internet References}

Globuchar, Amy (Senator) in the Congressional Hearings on Big Technology 17.11.20

Hunt, Rhian TMF Analyst: Amazon is Undervalued, Will Soar 40\% Higher Oct 12020

Review of Brave New World https: / / nanopdf.com/download/brave-new-world5aed15e520f3c_pdf 